Agricolaea fragrans Schrank, Denksch. Akad. Muench. 1808 p. 98 (reference not seen). Clerodendrum fragrans Willd. Enum. Hort. Berol. 659. 1809 (nom. illeg.).

Clerodendrum fragrans Aiton, Hort. Kew. 4: 63.1812 (not "R. Br. in Ait." nor "Vent. ex R. Br. in Ait.").

Clerodendrum fragrans var. multiplex Sweet, Hort. Brit. 322. 1827.

Clerodendron fragrans var. pleniflora Schauer, DC. Prodr. 11: 666. 1847.

Clerodendrum japonicum (Thunb.) Sweet var. pleniflorum (Schauer) Maheshwari, Taxon 15: 43.1966.

The single-flowered form is very well represented in collections from China and may deserve a varietal name. It should also be noted that the plant called Clerodendrum lindleyi often referred to the synonymy of "Clerodendrum fragrans" does not, in our opinion, belong there.

\title{
A PROPOSAL TO TREAT ORTHOGRAPHIC VARIANTS AS NOT VALIDLY PUBLISHED
}

\author{
Rogers McVaugh* and A. A. Bullock**
}

Recent proposals for the conservation of generic names have stimulated new discussion on a nomenclatural question that until recently could not be answered by recourse to the existing Code, namely the status of what have been called (Taxon 12: 291. 1963) "avowed or implied orthographic corrections" for previously published names.

The question is essentially this: Are orthographic corrections for previously published names to be considered as validly published (though illegitimate) new names? Or are they to be considered as "orthographic errors" and not really new names at all? If they are validly published they may be homonyms of later, legitimate names, and thus prevent the use of such later names. If they have been validly published they may be conserved. If on the other hand they are not validly published, then in effect they are not names, just as nomina nuda are not names in the sense of the Code. They cannot cause the rejection of later homonyms; under present interpretation of the Code they cannot be conserved.

There seems to have been nothing in the 1961 Code from which a decisive answer to the above question could be obtained, and nomenclatural opinion on the question has been sharply divided. In the discussion at Edinburgh, as well as in the mail vote that preceded the Congress, opinion was about evenly divided, but proposals to amend the existing Code were rejected. In the opinion of the Rapporteurs, as published in the Synopsis of Proposals (Regn. Veg. 30: 43. 1964), "It is ... not certain whether these detailed proposals constitute an improvement over the admittedly somewhat vague present rules".

\footnotetext{
* The Herbarium, University of Michigan, Ann Arbor, Mich., U.S.A.

** The Herbarium, Royal Botanic Gardens, Kew, Great Britain.
} 
In recent years a number of published articles have confirmed our opinion that it is impossible to make certain nomenclatural decisions on the basis of the current rules. Of these articles we need cite only two:

Stafleu and Rickett (Taxon 9: 158. 1960) regarded the conservation of Tripteris Less. (1831) as superfluous becauce a supposed homonym, Tripteris L. (1753) orth. mut. Thunb. (1817), was a [presumably unintentional] mis-spelling for Triopteris L. (1753). Proskauer, on the other hand (Taxon 10: 156. 1961), implied that if Thunberg intentionally used the spelling Tripteris, even if he attributed the changed spelling to Linnaeus, he thereby created a new and validly published name. Obviously there will be many instances in which it is impossible to determine the intent of a publishing author, and until 1966 the Code did not provide a means of choosing between possible alternatives.

In another case, Proskauer (Taxon 10:155-156. 1961) held that "Monocarpus Post \& Kuntze" (1903), a "correction" of Monocarpia Miq. (1865/6) was a validly published (though illegitimate) name and an earlier homonym of Monocarpus Carr (1956). Proskauer therefore proposed the name Carrpos to replace Monocarpus Carr. Post and Kuntze cited "Monocarpus Miq." and, as Proskauer said, "what they intended and thought they had done was to produce merely a correction of Miquel's name". Proskauer in essence took the point of view that the name Monocarpus Post \& Kuntze existed, it was validly published, and had to be considered for purposes of homonymy.

Bullock, in answer to Proskauer (Taxon 10:240-242. 1961), took the opposite point of view that "later orthographic variants must be regarded as orthographic errors and must be discarded unless the original spelling is itself shown to be either a typographic or an unintentional orthographic error; such later variants cannot be regarded as superfluous new names".

We see no way to resolve these differences of opinion by recourse to the 1961 Code. Under the one interpretation it is apparently possible to publish one or a number of substitutes for any generic name, for example, merely by changing the spelling. Even though Arts. 20,63 and 73 make it clear that the proposal of such substitutes is quite contrary to the rules, and that the substitutes ought not to be entitled to any standing under the Code, they are treated as validly published.

We feel that a way out of the difficulty may be found, in view of the following note, which was authorized by the Edinburgh Congress and appears in the 1966 Code:

Art. 14, Note 7. When a name is concerned only to preserve a particular orthography, it is to be attributed without change of priority to the author who originally described the taxon.

The implications that concern us here are two: 1) It is permissible under the Code to conserve a name merely to preserve a ceriain orthography, and 2) When this is done the "corrected" spelling (that is, the one that is conserved), is regarded not as a new name but as an emended version of the original one, and is therefore attributed to the original author.

It seems to us that a degree of precision and consistency may be attained by the logical extension of the above to include all cases of "avowed or implied orthographic corrections". Although this may be implicit in Art. 14, Note 7, we think it would be desirable to write into the Code an unequivocal statement that "corrections" are not validly published new names, that they do not exist nomenclaturally (as nomina nuda are not names in the sense of the Code), except that such orthographic variants may be conserved if it becomes desirable.

We acknowledge the force of the argument that only validly published names can be conserved, but we feel this can be provided for easily in the wording of an amend. 
ment to the Code. It does not seem contrary to the spirit of the Code to "preserve a particular orthography" (presumably one that is widely known and used), even if it is not technically (validly) published. As Conservation itself is a way of legalizing exceptions to the Code, we see nothing objectionable in another exception if it leads to eventual stabilization in nomenclature.

We therefore present the following proposal, adopted and modified from that made by Bullock in 1963 (Taxon 12: 289):

Proposal 105: Add the following to Art. 62:

Note. The publication of an avowed or implied orthographic correction of a previously published name does not constitute valid publication of a new name. Such later orthographic variants may be preserved only by conservation (cf. Art. 14, Note 7), or under the provisions of Art. 73.

Examples - "Lepidostemon Blume", adopted by Hasskarl (1844) is an error to be rejected in favor of Lepistemon Blume (1825) and is not a validly published name to be attributed to Hasskarl. Humiria Aublet (1775) is a conserved spelling (see Appendix III) introduced by Jaume Saint-Hilaire (1805) in place of the spelling "Houmiri" actually adopted by Aublet; it is not a new name to be attributed to Jaume Saint-Hilaire. Gluta benghas L. (1771) is an unintentional orthographic error, for $G$. renghas, as the vernacular name used as a specific epithet by Linnaeus was "Renghas", not "Benghas"; the name should be cited G. renghas L., as by Engler (1883).

\title{
THE HERBARIA OF MIAMI UNIVERSITY (MU) AND OBERLIN COLLEGE (OC) COMBINED
}

\author{
Harvey A. Miller *
}

During the symposium The Herbarium in the Modern University, Beaman, Rollins and Smith (1965) stressed the importance of the herbarium, its role in the university community, and Beaman concluded "... if taxonomy of the future is to flourish, the physical resources which the herbarium represents must develop accordingly."

The new, completely air-conditioned, herbarium of Miami University, which has both physical and human resources, was occupied in 1966 but final organization of materials is still in progress. The storage area is comprized of three levels in two stories with windows in only the upper level. Each floor has a capacity for 78 standard metal herbarium cases and has an automatic individually-activated sprinkler system. Shelves and counter space are provided on each level (Fig. 1) and a dumb waiter assists with transfer of large lots of specimens.

The adjacent preparation room is about $18 \times 37 \mathrm{ft}$ and contains a forced air, vented, drying cabinet capable of holding some $14 \mathrm{ft}$ of plants presses at one time (Fig. 2). The Cincinnati Sub-Zero Company vacuum fumigation chamber designed by the author has a capacity of $23 \mathrm{cu} \mathrm{ft}$ and effective fumigation is possible, using carbon tetrachloride saturated with paradichloro-benzene, in as little as four hours.

\footnotetext{
* Present address: Department of Botany, Washington State University, Pullman, Washington 99163, U.S.A. Final intercalation, repair, and accessioning of the Oberlin collections is assisted by National Science Foundation Grant GZ-689.
} 